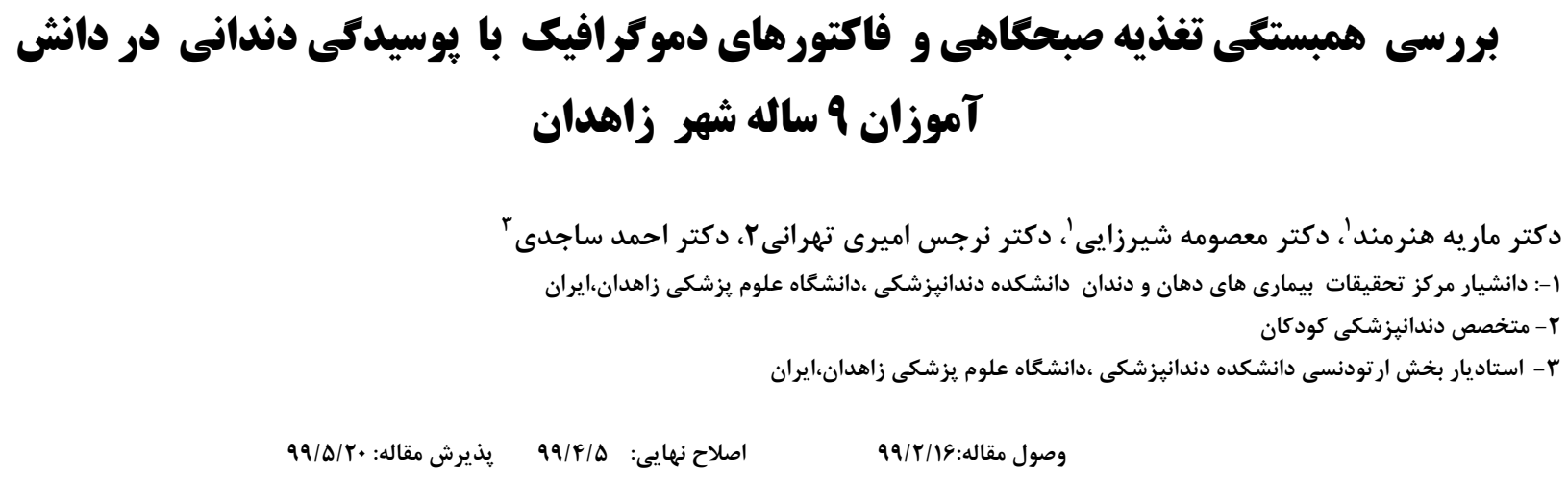

\title{
Assessment the correlation of Morning Nutrition and Demographic Factors with Dental Caries in 9-year-old Students in Zahedan city
}

\author{
Marieh Honarmand ${ }^{1}$, Masoumeh Shirzaiy ${ }^{1}$, Narjes Amiri Tehrani ${ }^{2}$,Ahmad Sajedi ${ }^{3}$ \\ ${ }^{1}$ Associated professor, Oral and Dental Disease Research Center ,Dental school, Medical science ,Zahedan,Iran \\ ${ }^{2}$ Pediatric dentistry specialist \\ ${ }^{3}$ Assistant professor, Orthodontia Department ,Zahedan Dental school, Medical science ,Zahedan,Iran
}

\section{Abstract}

Received:May 2020

; Accepted: July 2020

Background and Aims: Dental caries is a multi-factorial disease Demographic factors, also diet particularly breakfast which is an important meal are factors affecting the level of dental caries. The purpose of this study was investigation relationship between morning feeding and other demographic factors with tooth decay in 9 years old Zahedan students

Materials and Methods: In This descriptive - analytical and cross-sectional study, Zahedan city divided into four regions based on population table.From each region one public and private school (boy \&girl), randomly selected,. for 400 boy\& girl students 9 years old was filled the questionnaire about demographic factors, and breakfast consumption and oral examination was done for evaluation of $\mathrm{dmft}$, DMFT and OHI-s criterias by a dentist . Data were analyzed with soft ware spss 21 and t-test, ANOVA and Pearson correlation..

Results: The Mean dmft, DMFT in children served breakfast $(5.22 \pm 2.5$ and $1.34 \pm 1.4$ ( and in children did not consume breakfast ( $4.5 \pm 2.5$ and $1.39 \pm 1.44)$ had no significant difference $(\mathrm{p}>0.05)$ but the mother's occupation and, father education had significant correlation with DMFT and mother education had significant correlation with DMFT, dmft $(\mathrm{P}<0.05)$

Conclusion: breakfast consumption and its type was not effective in reducing the level of dental caries. Children with educated mothers had low permanent and insidious dental caries and tooth decay was significantly lower in children with employer or teacher mothers and educated fathers .

Key Words: Dental Caries, Nutrition, Oral Health

*Corresponding Author: shirzaiy@gmail.com

J Res Dent Sci. 2020; 17 (3): 208-218 
سابقه و هدف: يوسيدگى دندانى يك بيمارى مولتى فاكتوريال مى باشد. فاكتورهاى دموَرافيك و نيز رزيم غذايى بويزه صرف

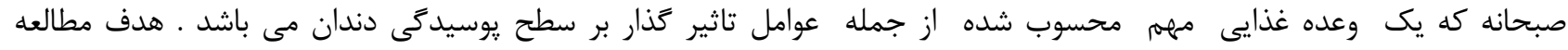

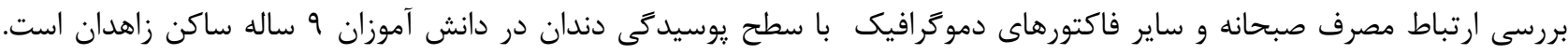

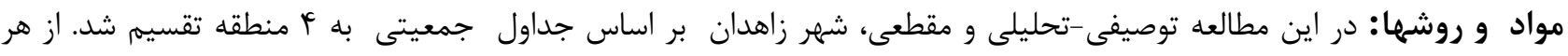

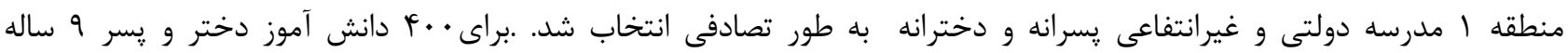

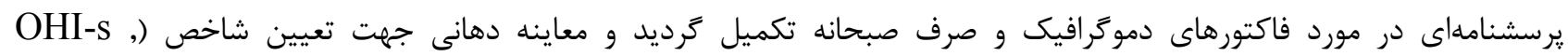
Pearson و ANOVA،t-test و و آزمونهاى Spss Imft,DMFT correlation

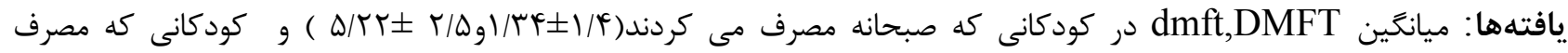
نمى كردند(

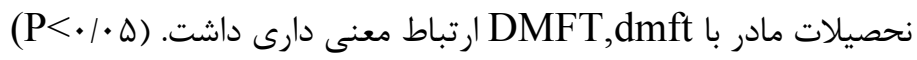

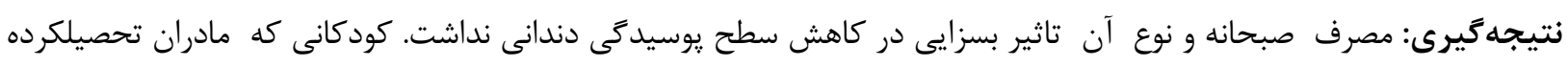

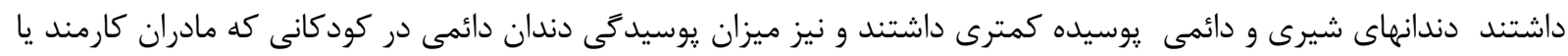
فرهنكى و نيز يدران تحصيلكرده داشتند به طور مشخصى كمتر بود. كليد وازهها: يوسيدگى دندانى، تغذيه ، سلامت دهان

مقدمه:

طى مطالعات حيوانى و انسانى مشخص گرديده كه با افزايش دفعات مصرف شيرينى ، شيوع يوسيدگى افزايش يافته و دفعات مصرف شيرينى نسبت به ميزان مصرف، فاكتور اتيولوزيك مهمترى ترى در ايجاد يوسيدكى مى باشد. (f-1) و همكاران با بررسى رابطه بين عادات تغذيهاى سالم و يوسيدكى دندان در كودكان ه-r ساله به اين نتيجه رسيد كه،

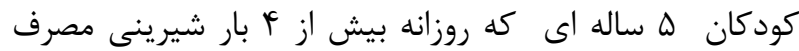

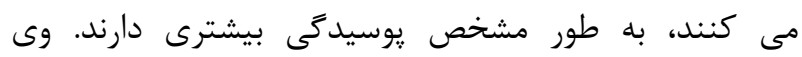
كزارش نمود ، مصرف صبحانه و ه وعده ميوه و سبزى، عادات

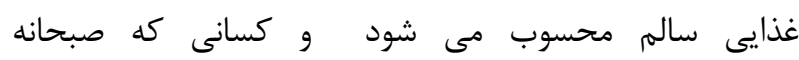
نمى خورند، يوسيد و همكاران تزارش كردند، اكثر كودكان Oosthuizen دبستانى مواد شيرين همجون كيك) (mean =59 g) شيرينى (mean = 316g) وصرف اسكواش (mean=41 g) مى كنند ("). مطالعهاى روى 11 مدرسه در Pietermaritzburg (Wiles,2011)
يوسيدگى دندانى يكى از شايع ترين بيمارى هاى مزمن

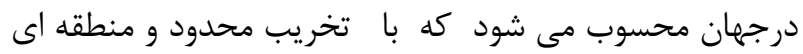
بافت هاى آهكى دندان مشخص مى كردد. (r-1) عوامل متعددى همجون ميزبان ، سوبسترا (ماده غذايى)، باكترى، اسيداوريك و زمان برشروع و ييشرفت يوسيدگى مؤثر

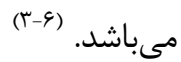
كربوهيدراتها، سوبستراى مناسبى جهت باكتريهاى يوسيدىى زا بويزه استريتوكى موتانس مى باشد.يوسيدگى دندان شايع ترين بيمارى دوران كودكى است كه در آن اسيد توليد شده ناشى از متابوليسم كربوهيدراتهاى قابل تخمير به به وسيله باكتريها و ميكرواركانيسمهاى موجود در بزاق دهان از جمله

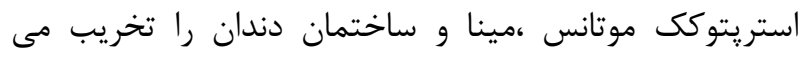
كند. (- n رزيم غذايى بويزه تركيبات حاوى شكر يكى از مهمترين عوامل مولد يوسيدگى مى باشد مصرف ميان وعده هاى شيرين ميزان

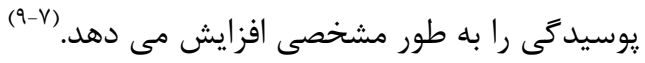


امار دقيقى در مورد مصرف صبحانه در كودكان دبستانى در دسترس نيست، نتايج مطالعات بررسى كننده ارتباط رزيم غذايى با يوسيدگى در دوران ڤيش دبستانى و دبستانى بسيار

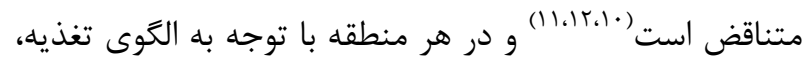
بهداشت و وضعيت فلورايد فرق مى كند.همجنين مطالعات جامعى در زمينه فاكتورهاى موثر بر :يوسيدگى دندانى در كودكان وجود ندارد. لذا اين مطالعه با هدف تعيين ارتباط مصرف صبحانه و ساير فاكتورهاى دموگرافيك با يوسيدگى دندانى در دانش آموزان 9 ساله شهر زاهدان انجام شد.

\section{مواد و روش ها: - ماد}

در اين مطالعه توصيفى-تحليلى و cross sectional ، از تكنيك مشاهده، مصاحبه و تكميل يرسشنامه جهت جمعآورى اطلاعات استفاده گرديد. نمونه مرحله اى انجام شد.بتدا شهر زاهدان بر اساس نمودارها و جداول جمعيتى به fl منطقه تقسيم شد. يس از هماهنگیى با اداره كل آموزش و يرورش استان و كسب اطلاعات در مورد تعداد و محل مدارس ابتدائى ، مدارس ابتدايى دولتى و غيرانتفاعى يسرانه و دخترانه هر منطقه كد گذارى شده و با لـ استفاده از جدول اعداد تصادفى، در هر منطقه يك مدرسه

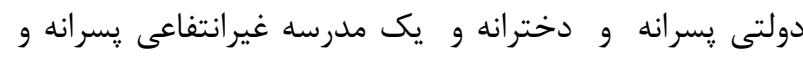
دخترانه انتخاب گرديد.يس از هماهنگى با مديران مدارس تعداد له دانش آموز 9 ساله از هر مدرسه به صورت تصادفى انتخاب شد. تعدادى از كلاسهاى يايه سوم بهطور تصادفى انتخاب و

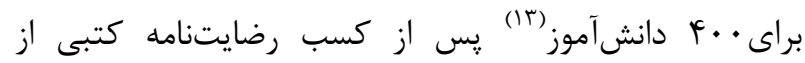
والدين و در صورت تمايل به همكارى (تعدادى از دانشآموزان دختر به دليل عدم همكارى از مطالعه خارج شدند). در حضور يكى از والدين يرسشنامه (حاوى اطلاعات دموگرافيك،الگوى مصرف صبحانه و رفتارهاى بهداشت دهان شامل مسواى زدن و استفاده از خمير دندان) تكميل گرديد . روايى(بر اساس ضرايب CVI, CVR) و رِايايى سوالات توسط متخصصين مجرب دندانيزشكى كودكان و متخصصين تغذيه(آلفاى
اضافى از نوشيدنى ها ، آب ميوه هاى مخلوط و شيرهاى طعم دار در مدرسه دريافت مى كنند كه در صورت مصرف صبحانه اين ميزان به طور تُشمگيرى كاهش مى يابد. برخى مطالعات اخير نشان مى دهد ،صرف صبحانه مى تواند ميزان وقوع يوسيدگى را به طور مشخص افزايش دهد، همجنين فاكتورهاى دموكرافيك مانند رفتارهاى بهداشتى و شغل و تحصيلات والدين نيز در اين زمينه موثر است. (Irا.|l) Monteagudo دبستانى و ارتباط آن با يوسيدگى دندانى دريافتند كه مصرف صبحانه بويزه صبحانه شيرين ارتباط بارزى با افزايش ميزان يوسيدگى دندانى دارد. (II) Bae و همكاران نيز دريافتند صبحانه حاوى كربوهيدراتهاى شيرين مى تواند موجب افزايش وقوع يوسيدگى شود .در مطالعه آنها سطح تحصيلات والدين ارتباط مشخصى با كاهش يوسيدگى (بويز در קسران) داشت.با اين وجود تحصيلات يدر

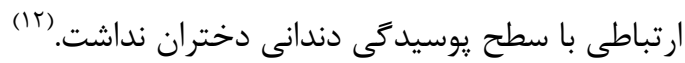
تحصيلات دانشخاهى والدين ، مى تواند نقش بسزايى در افزايش آكاهى نسبى آنها در رابطه با بهداشت دهان و دندان و عوامل اتيولوزيك يوسيدگى دندانى داشته باشد و بر سلامت دهان و دندان فرزندان مؤثر است Basha و همكاران طى يك مطالعه دريافتند وضعيت اقتصادى اجتماعى يايين و سطح تحصيلات مادر ارتباط مشخصى با سطح يوسيدگى دندانى كودكان

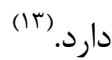
بهبود سلامت دهانى كودكان، نيازمند بررسى دقيق رزيم غذايى مى باشد. زيرا عادات غذايى در دوران كودكى معمولا تا بزرگسالى ادامه مى يابد برخوردارى از يك برنامه ى غذايى متعادل، مواد لازم رابراى تأمين سلامت كلى بدن و نيز سلامت دهان و دندان فراهم مى سازد. بى شك عادات غذايى نادرست و روى آوردن كودى به تنقلات شيرين و كاهش مصرف مواد غذايى اصلى همجون صبحانه، اثراتى جبران نايذير بر سلامت عمومى كودى مى كذارد و زمينه را براى ايجاد يوسيدگى

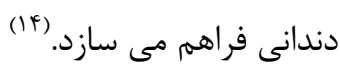




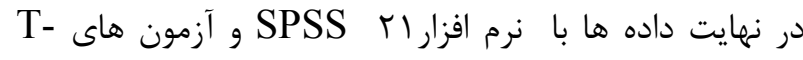
و و همبستگى ركرسيون (ييرسون) آناليز گرديد. سطح معنى دارى كمتر از هـ • • در نظر

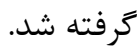

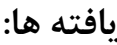

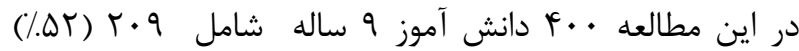

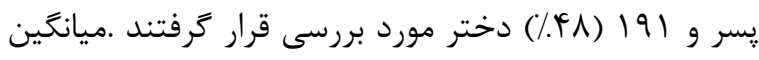

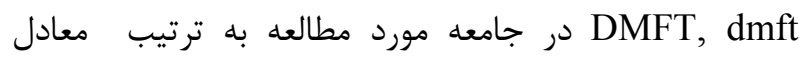

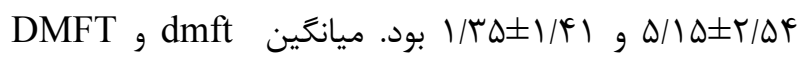
دريسران به ترتيب معادل

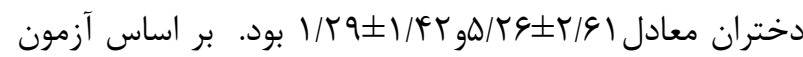
ميانكين D-test معنى دارى نداشت (DMFT $t=\bullet$ و $(\mathrm{dmft} \quad \mathrm{t}=-\cdot / \wedge \& \quad \mathrm{P}$ در جامعه مورد مطالعه ،شغل يدر كه جزيى از فاكتورهاى اقتصادى - اجتماعى محسوب مىشود، از عوامل تاثيرگذار بر مورد

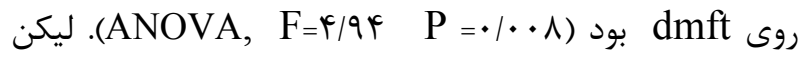
ميان شغل يدر و DMFT ارتباط معنى دارى وجود نداشت ( (ANOVA F=I/Fq $\mathrm{P}=$ ()/ (Tr)
كرونباخ) تأييد كرديد. سوالات مربوط به الكَى مصرف

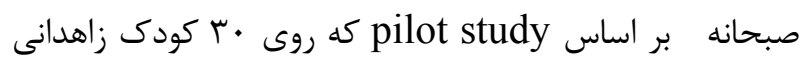
(با همكارى متخصص تغذيه) انجام شده بود، تعيين گرديد.

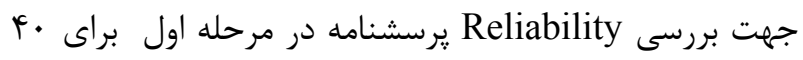

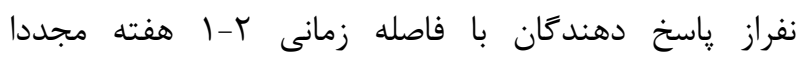
يرسشنامه تكميل كرديد. اطلاعات عمومى دانش آموز با استفاده از شناسنامه سلامت فرد تكميل كرديد. صبحانه مصرفى به دو گروه صبحانه شيرين( مربا، عسل، حلوا شكرى و جاى شيرين) و غير شيرين( نان، كره، ينير، خامه، شير و تخم مرغ) تقسيم گرديد..جهت تكميل اين بخش از يرسشنامه الكوى مصرف صبحانه طى هفته كذشته مد نظر قرار مى كرفت. معاينه دانش آموزان در ساعت 9 صبح (قبل از شروع زنغ تفريح دوم) روى يك صندلى معمولى با نور head light (ساخت

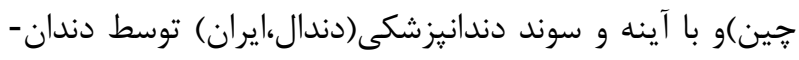
يزشك صورت كرفت. تشخيص يوسيدكى دندانى بر اساس معيارهاى سازمان جهانى بهداشت انجام گرفت يوشش دندان با دبرى و عدم مشاهده يوسيدگى، دبرى هاى

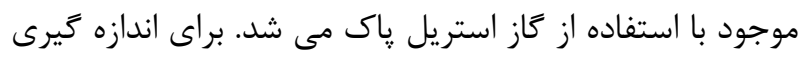

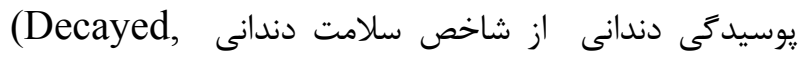
dmft,DMFT :Missing and Filling Teeth Index)

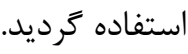
براى ارزيابى سلامت لثه از يروب WHO ايران سبك وزيدن باد بان

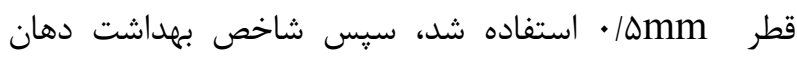
تعيين شد (OHI-S) شاخص دبرى DI-S و جرم CI-S تعيين شد كه مجموع آن تعين

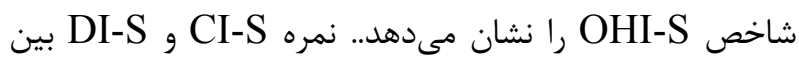

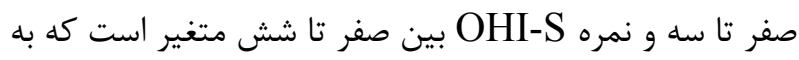
صورت زير تقسيم بندى شد خوب رنج بين // ا-• متوسط بين

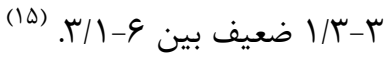


در مطالعه كنونى ميانگين در كودكانى كه مادران تحصيلكرده داشتند كمتر بود و ارتباط معنى دارى ميان شاخص سلامت دندانى شيرى و دائمى (DMFT , dmft ) و سطح تحصيلات وجود داشت. (ه $)$ در مطالعه حاضر، YYY نفر (\$N/D./) روزانه Y بار مسواك

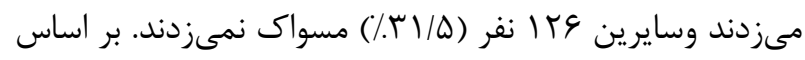
آزمون T-test ارتباط معنى دارى ميان مسواك زدن و دفعات مسواك زدن و DMFT, dmft وجود نداشت. (ه •/ P

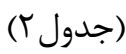
جدول r- ارتباط بين متغيرهاى مورد مطالعه(صرف صبحانه و نوع

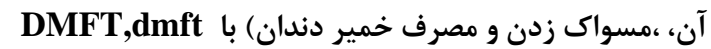

\begin{tabular}{|c|c|c|c|c|}
\hline متغير & טاسخ & (\%) تعداد & DMFT & Dmft \\
\hline مسواك & بله & $\operatorname{rVF}(\xi N / \Delta)$ & $1 / r \Delta \pm 1 / F r$ & $\Delta / r Y \pm T / \Delta$ \\
\hline زدن & خير & $\mid r \xi(\Gamma \mid / \Delta)$ & $1 / r F \pm .1 / 4 r$ & $r / 9 \Lambda \pm r / q r$ \\
\hline \multirow{2}{*}{\multicolumn{2}{|c|}{ آزمون }} & & $\mathrm{t}=\cdot / \cdot 1$ & $\mathrm{t}=\cdot / \wedge 9$ \\
\hline & & T-test & $\mathrm{P}=\cdot / 94$ & $\mathrm{P}=\cdot / r V$ \\
\hline استفاده از & بله & $r V I(\& V / V)$ & $1 / T \Delta \pm 1 / F r$ & $\Delta / r \Psi \pm r / 4 q$ \\
\hline خدمير & خير & $1 r q(r r / T)$ & $1 / r f \pm .1 / f$ & $r / 9 \Lambda \pm r / q r$ \\
\hline
\end{tabular}

\begin{tabular}{|c|c|c|c|c|}
\hline \multicolumn{2}{|c|}{ آزمون } & T-Test & $\begin{array}{l}\mathrm{t}=\cdot / \cdot 1 \\
\mathrm{P}=\cdot / 99\end{array}$ & \multirow{2}{*}{$\begin{array}{c}\mathrm{t}=\cdot / 91 \\
\mathrm{P}=\cdot / r \varphi \\
\Delta / r r \pm r / \Delta r\end{array}$} \\
\hline مصرف & بله & rgr $)(\cdot(\Delta)$ & $1 / \mu F \pm .1 / 41$ & \\
\hline صبحانه & خير & $r \wedge(9 / \Delta)$ & $1 / r q \pm .1 / 4 q$ & $r / \Delta \pm r / \Delta q$ \\
\hline \multirow{2}{*}{\multicolumn{2}{|c|}{ آزمون }} & & $\mathrm{t}=\cdot / \mathrm{r}$ & $\mathrm{t}=-1 / 99$ \\
\hline & & T-test & $\mathrm{P}=\cdot / \lambda r$ & $\mathrm{P}=\cdot / \cdot 9$ \\
\hline نوع صبحانه & شير & (9וא) & $1 / r V \pm .1 / 4 T$ & $\Delta / r \pm \Gamma / \Delta \Delta$ \\
\hline
\end{tabular}

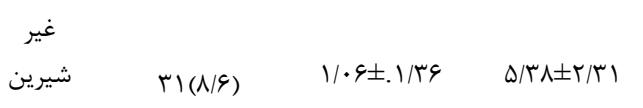

\begin{tabular}{|c|c|c|c|c|}
\hline \multicolumn{2}{|c|}{ آزمون } & T-test & $\begin{array}{l}\mathrm{t}=l / l Q \\
\mathrm{P}=\cdot / \pi f\end{array}$ & $\begin{array}{l}\mathrm{t}=-\cdot / \mathrm{N} \\
\mathrm{P}=\cdot / \mathrm{V}\end{array}$ \\
\hline \multirow[t]{2}{*}{ OHI-s } & خوب & $1 \cdots(r \Delta)$ & $1 / 4 q \pm 1 / \Delta$ & $r / \Lambda \varepsilon \pm r / \Delta \Delta$ \\
\hline & متوسط & $r q f(V / \Delta / \Delta)$ & $1 / r q \pm 1 / \Delta$ & $\Delta / r \Lambda \pm \Gamma / \Delta r$ \\
\hline \multirow{2}{*}{\multicolumn{2}{|c|}{ آزمون }} & T-test & $t=1 / 10$ & $t=-I / Q r$ \\
\hline & & & $\mathrm{P}=\cdot / \pi F$ & $\mathrm{P}=\cdot / / \mathrm{r}$ \\
\hline
\end{tabular}

جدول ا -ار تباط بين متغير فاكتور راى اقتصادى -اجتماعيبا DMFT,dmft

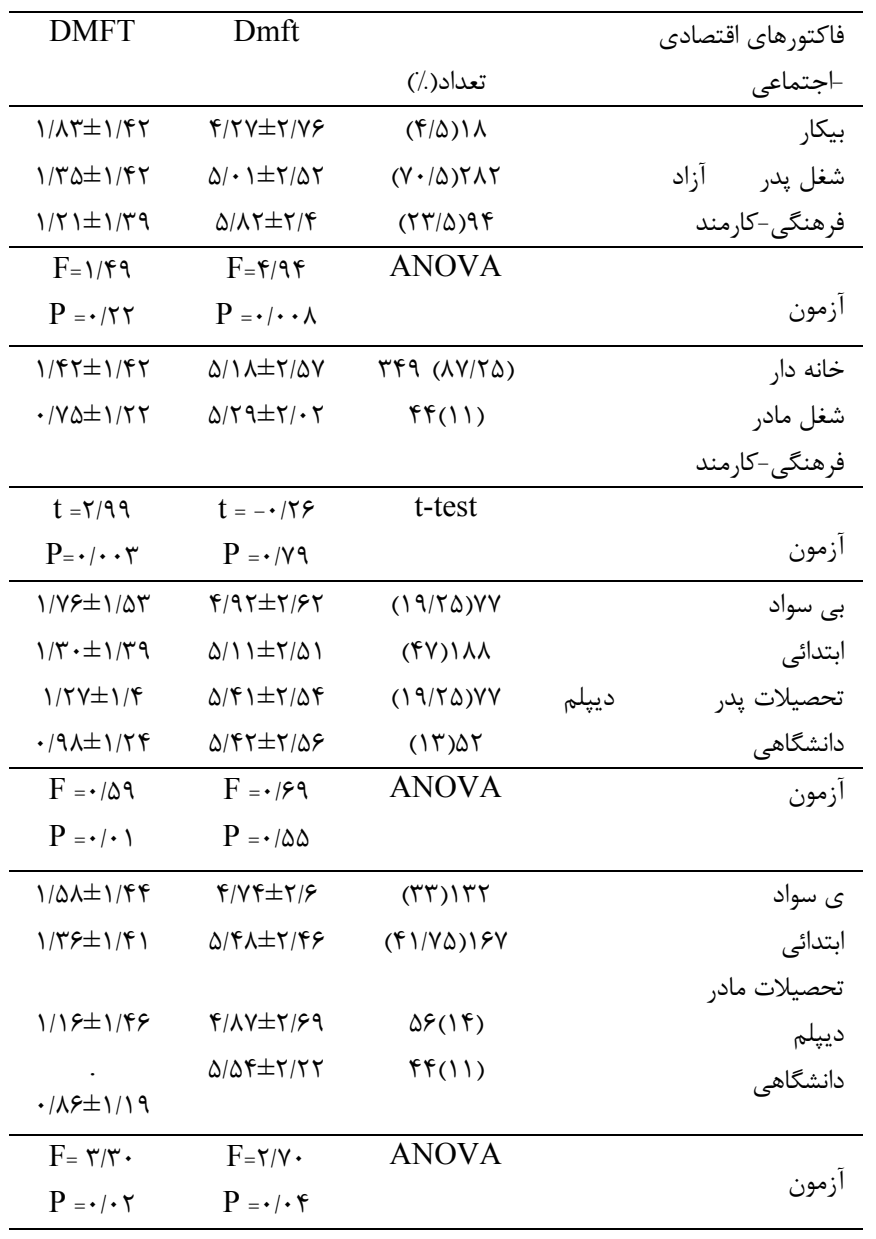

در ابن مطالعه فرزندان مادران كارمند يا فرهنگى يوسيدگى كمترى داشتند و ميانگين DMFT در آنها پايينتر

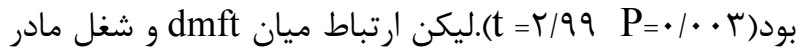

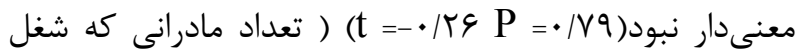
آزاد داشتند، 9 نفر بود، بنابراين از آناليز دادهها در اين گروه صرف نظر شد) (جدول () در مطالعه كنونى ميانگين DMFTدر كودكانى كه يدرانشان تحصيلات دانشغاهى داشتند كمتر بود و ارتباط معنى دارى ميان DMFT و سطح تحصيلات وجود داشت (1 P (1) و dmft ليكن ارتباط معنى دارى بين ANOVA F =•/ 109 F = سطح تحصيلات وجود نداشت. (199 
در اين مطالعه ارتباط معنى دارى ميان استفاده از خمير دندان همجنين استفاده از خميردندان در دختران به طور معنى دارى

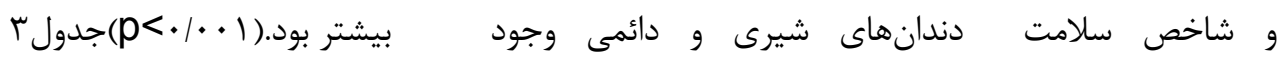

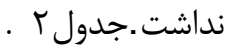

جدول r- ارتباط بين متغيرهاى مورد مطالعه(صرف صبحانه و نوع آن، ،مسواك زدن و مصرف خمير دندان) با جنس

\begin{tabular}{|c|c|c|c|c|c|c|c|}
\hline \multirow{4}{*}{ متغير } & \multirow{2}{*}{\multicolumn{2}{|c|}{ ياسخ }} & \multirow{2}{*}{\multicolumn{2}{|c|}{ 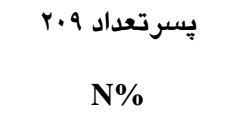 }} & \multirow{2}{*}{\multicolumn{2}{|c|}{ تعداد | 19 | }} & $\mathbf{p}$ \\
\hline & & & & & & & (chi-square) \\
\hline & \multicolumn{2}{|c|}{ N\% } & & & \multicolumn{2}{|c|}{ N\% } & \\
\hline & بله & خير & يله & خير & بله & خير & \\
\hline \multirow[t]{2}{*}{ صرف صبحانه } & זרז & rی & $M A T$ & rv & $1 A$. & 11 &.$/ \cdot 1$ \\
\hline & $\% 9 \cdot 10$ & $9 / 0$ & $\% \wedge \vee / \Lambda$ & $\% 1 Y / 9$ & $\% 9 r / r$ & $\% \Delta / \Lambda$ & \\
\hline \multirow[t]{2}{*}{ صبحانه شيرين } & rl & ו וr & ro & $10 \mathrm{~V}$ & 4 & IVF & $<\cdot / \cdot+1$ \\
\hline & $\%$ N/9 & $\% 91 / 4$ & $\mid r / v$ & $\% \wedge \varepsilon / \Gamma$ & $\% r / r$ & $\% 97 / V$ & \\
\hline صبحانه غير & ו וrr & r & $10 V$ & ro & IVF & 4 & $<\cdot / \cdot+1$ \\
\hline شيرين & $\% 91 / 4$ & $\% / / 9$ & $\% \wedge \varepsilon / r$ & $\% 1 r / v$ & $94 \% / V$ & $\%$ & \\
\hline \multirow[t]{2}{*}{ مسواك زدن } & TVY & Irs & IrT & Av & lor & rq & $<\cdot / \cdots 1$ \\
\hline & $\%$ \%/。 & $\%$ Tr/o & $\% \circ \Lambda / \varepsilon$ & $\%+1 / 4$ & $\% \vee 9 / 7$ & $\% \cdot / \varepsilon$ & \\
\hline استفاده از خمير & rWI & $1 r q$ & ir. & 19 & 101 & t. & $<\cdot / \cdot \cdot 1$ \\
\hline 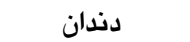 & $\% \& V / A$ & $\% r r / r$ & $\% \Delta V / P$ & $\% \Psi r / 9$ & $\% \vee q / 1$ & $\% r \cdot / 9$ & \\
\hline
\end{tabular}


والدينشان تحصيلات دانشعاهى داشته يا مادران كارمند يا

فرهنگى داشتند، مشاهده شد. و Bae,، (rv) Campus, و همكاران Marshal

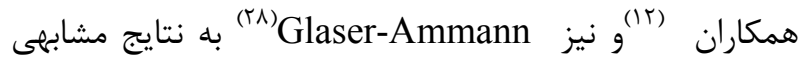
دست يافتند ،ليكن در مطالعه Freeman و همكاران (ra) رابطه مشخصى بين سطح تحصيلات والدين و شاخص يوسيدىى وجود نداشت. در مطالعه Bae بطور مشايهى سطح تحصيلات والدين ارتباط مشخصى با كاهش يوسيدگى (بويز در يسران) داشت ليكن سطح تحصيلات يدر ارتباطى با ميزان وقوع يوسيدگى در

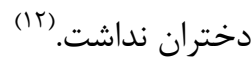
تحصيلات دانشخاهى والدين ، ميزان آكاهى نسبى آنها رادر

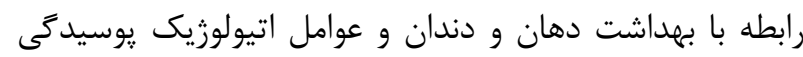

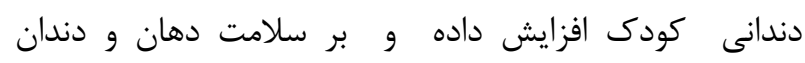
فرزندان مؤثر مى باشد. در مطالعهاى در اردن، آكاهى والدين

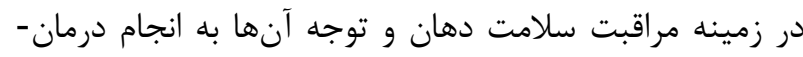
هاى دندانيزشكى بر روى مراقبتهاى دندانى فرزندشان، تاثير به سزايى داشت. (TV) وضعيت اشتغال والدين، يِشكويى كننده قوى رفتارهاى بهداشت دهان كودكان است، ليكن Taani (•r) تزارش كرد، ارتباط مشخصى بين اين دو فاكتور وجود ندارد و آموزش

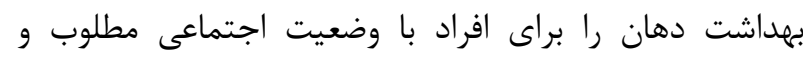

نامطلوب توصيه نمود.

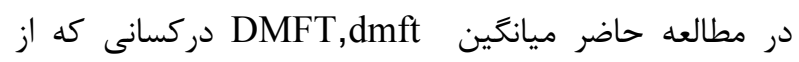
مسواى و خمير دندان استفاده مى كردند تفاوتى با سايرين

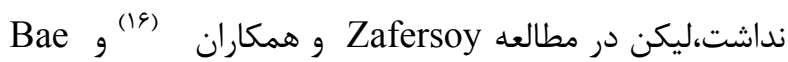
وهمكاران مسواك زدن موجب كاهش ميانگين DMFT و

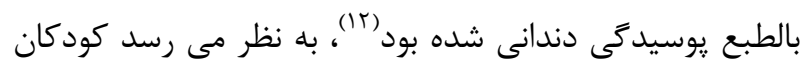
9 ساله مورد مطالعه رفتارهاى بهداشت دهان را به طور موثر انجام نمى دهند و مى بايست جهت كاربرد روشهاى صحيح مسواى زدن آموزشهاى لازم در مدرسه توسط مربى بهدئ بهاشت

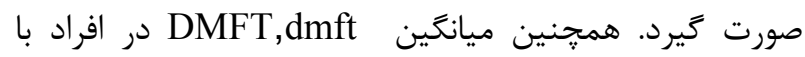
شاخص بهداشت دهان خوب و متوسط تفاوتى با يكديكر
در مطالعه حاضر فاكتورهاى دموكرافيك به عنوان فاكتورهاى زمينه اى يا مداخله گر بر يوسيدگى در كنار مصرف صبحانه برسى شد.

شاخص سلامت دندانى بك جامعه، نشان دهنده ميزان واقعى يوسيدگى و اقدامات ييشخيرانه انجام شده مى باشد. در مطالعه حاضر ميانگين dmft و DMFT در جامعه مورد مطالعه به ترتيب معادل dmft,DMFT با مطالعه Zafersoy و همكاران كه ارتباط عادتهاى تغذيه اى و رفتارهاى بهداشت دهان را با DMFT در بيماران جوان دندانيزشكى بررسى نمودند و نيز مطالعه Bae و همكاران Al- ${ }^{(I V)}$ Eslamipour مطابقت نيز به نتايج مشابهى در اين زمينه دست يافتند Rafee ليكن نتايج برخى مطالعات حاكى از آن است كه در سنين ه سالخى ميزان شيوع يوسيدگى در پِران بيشتر است، ليكن در سن rا سالتى بالعكس ميزان : يوسيدگى در دختران (بدليل رويش سريعتر دندانهاى دايمى نسبت به يسران) افزايش مى (هى

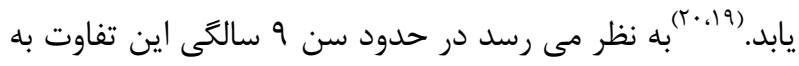
حداقل مى رسد.زيرادر مطالعه حاضرارتباطى بين جنس وشيوع يوسيدگى وجود نداشت. شاخص بهداشت دهان در مطالعه حاضر بر اساس معيار هایWHO در حد متوسط است. اين يافته مشابه نتايج

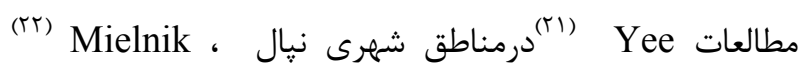
درlublin درحالى كه در مطالعه ullah دهان كودكان ضعيف ارزيابى گرديد. برعكس وضعيت بهداشت دهان بجه هاى إ ساله روستايى و مدارس غير دولتى نيال،

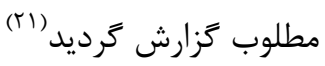
شغل و تحصيلات والدين ، فاكتورهاى تعيين كننده وضعيت اجتماعى ـ اقتصادى فرد مىباشد. (rه) در مطالعه حاضر، سطح تحصيلات والدين و شغل مادر ارتباط معنىدارى، با DMFT داشت و كمترين ميزان يوسيدگى در دانش آموزانى كه 
از طريق بوفه مدرسه، هزينه و طعم و مزه مواد و عدم آكاهى والدين در مورد مضرات اين مواد اشاره نمود.

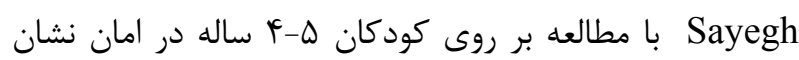

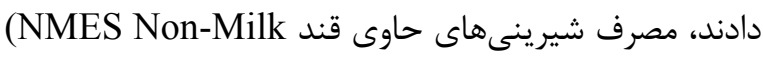
Extrinsic Sugars)

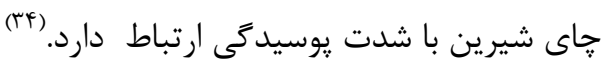

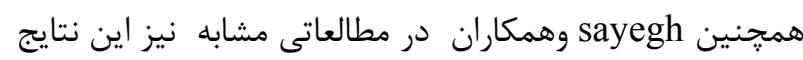

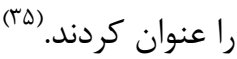
و و همكاران Levine

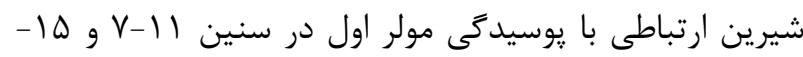
11 سالكى ندارد، بلكه نوشيدنى هاى شيرين موجب افزايش يوسيدگى در اين دندانها مى شود.

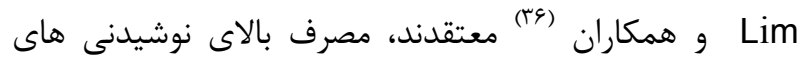

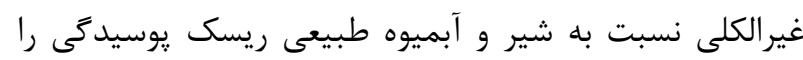
افزايش مى دهد. مصرف صبحانه كه يك وعده غذايى مهم محسوب مى شود در

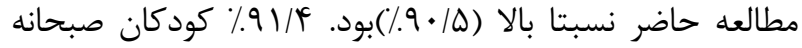
غير شيرين مصرف مى كردند و دختران تمايل بيشترى براى صرف صبحانه داشتند.عليرغم مصرف بالاى صبحانه غير شيرين در مطالعه حاضر،مصرف اين وعده غذايى و نوع آن تاثيرى روى صرى

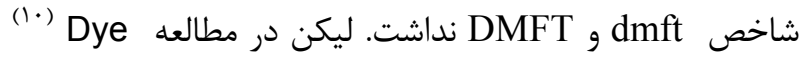
كودكان U-T ساله اى كه صبحانه نمى خوردند، يوسيدگى بيشترى داشتند و ارتباط معنىدارى بين مصرف صبحانه و سطح يوسيدگى وجود داشت و نيز درمطالعه - Bruno Ambrosius نوجوانان سوئدى ارتباط مشخصى با سطح يوسيدگى داشت.

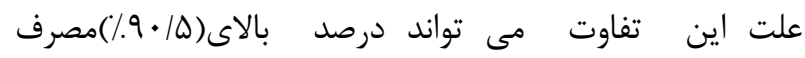

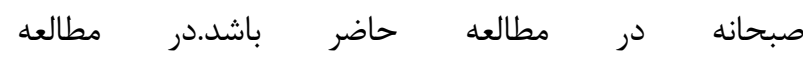
Bruno-Ambrosius,

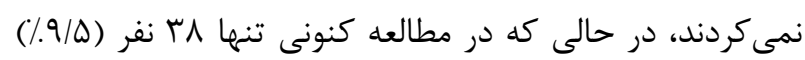

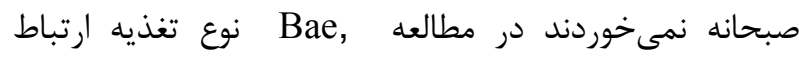

نداشت.Wang, (") Bruno - Ambrosius (19) مشابهى دست يافتند .ليكن در مطالعه Zafersoy (19) افزايش به نايج

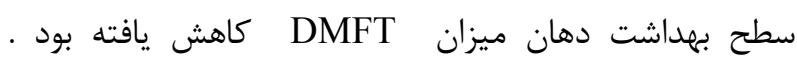

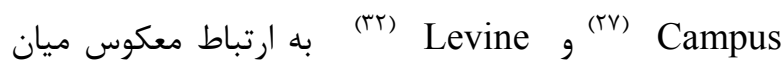
شاخص DMFTو مسواك زدن و رعايت بهداشت اشاره نموده

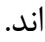
در مطالعه حاضر ساير روشهاى بهداشت دهان بررسى نشده است، با توجه به اينكه دهانشويه فلورايد در تمامى مدارس ابتدائى زاهدان براى كودكان تجويز مى كردد، استفاده از دهان شويه فلورايد در مدارس نيز مى تواند موجب كاهش فاصله DMFT Zafersoy بهداشت دهان زيرداخته بودند، ززارش نمودند، نوع تغذيه مهمترين عامل تاثير كذار بر روى DMFT مى باشد. وى اظهار نمود در افرادى كه رفتارهاى بهداشت دهان مشابه دارند، يكى از علل ايجاد يوسيدگى، مصرف تنقلات بين وعده شيرين مى باشد كه موجب مى شود ، عليرغم روشهاى صحيح مسواك زدن ميزان DMFT در اين افراد بيشتر باشد. اين در حالى است كه Bruno - Ambrosius مزارش ميرن نمودند ارتباطى بين مصرف بالاى تنقلات ، نوشيدنى هاى غير الكلى و شيرينى، وجود ندارد . در مطالعه وى حذف بـ صبحانه نسبت به مصرف تنقلات تاثير بيشترى درايجاد يوسيدىى

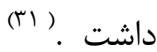
Punitha همكاران با بررسى نقش عادات تغذيه اى و رزيم غذايى در وقوع وشدت يوسيدكى در دانش آموزان دريافتند كه رزيم غذايى و تغذيه تاثير بسزايى در ميزان وقوع يوسيدكى دارد و مصرف نوشيدنيهاى شيرين،snack fast food و به طور بارز ميزان يوسيدگى را افزايش مى دهد.

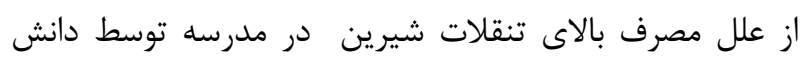
آموزان مى توان به عدم مصرف صبحانه كامل ، دسترسى آسان 
دندانى مختلط) ارزيابى شده بود ،در حاليكه در مطالعه

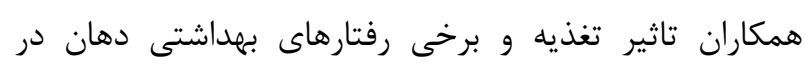

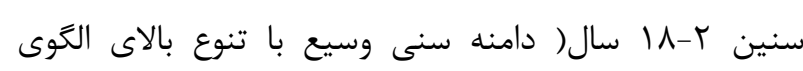

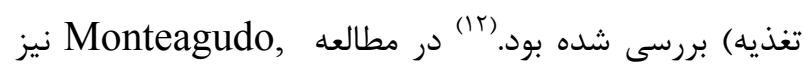
تنها مصرف صبحانه و رفتارهاى بهداشت دهان در كودكان ندان

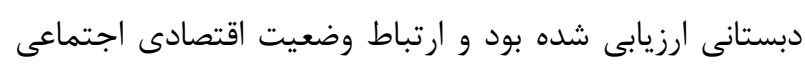
دانش آموز كه مى تواند در زمينه تغذيه فرد، دسترسى يه رونيه

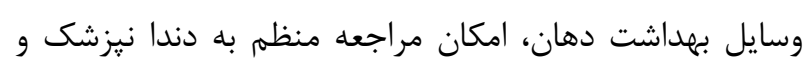

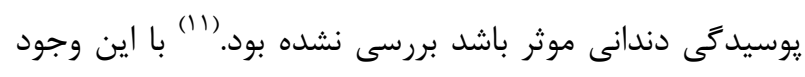

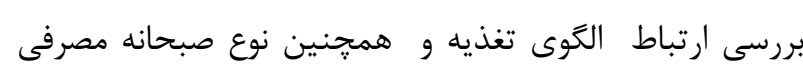

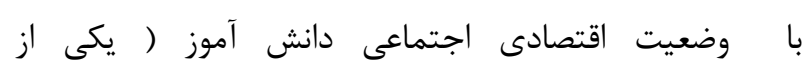

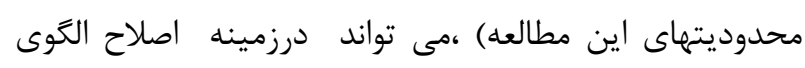
غذايى و در نتيجه كاهش وقوع يوسيدگى دندانى بسيار موثر باشد .

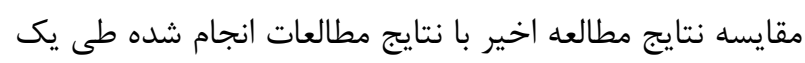

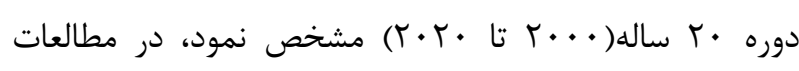

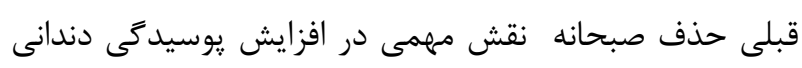

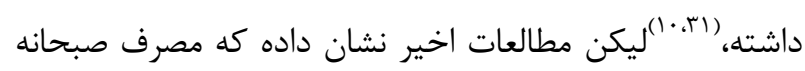

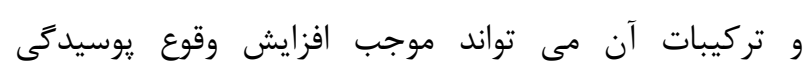

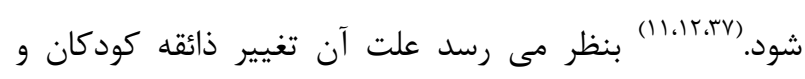

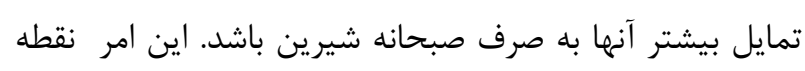

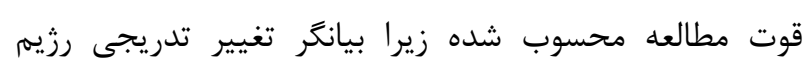
غذايى كودكان مى باشد.

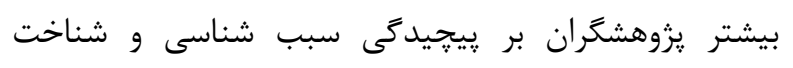

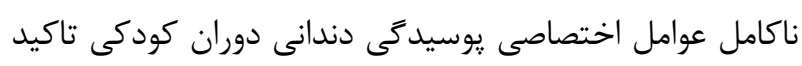

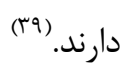
يردازش برنامه عى غذايى كودكان هر جامعه مى تواند در ارزيابى

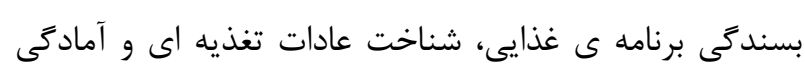

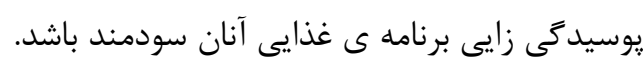

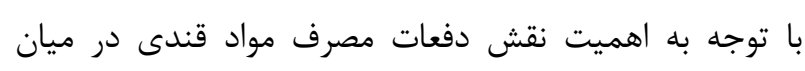

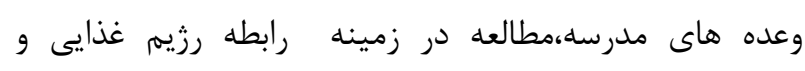
يوسيدگى دندان توجه خاصى را به خود معطوف ساخته است.

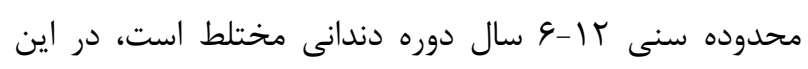

مشخصى با ميزان وقوع يوسيدگى داشتبدين صورت كه مصرف صبحانه و دفعات آن تاثير بارزى در وقوع يوسيدگى بونى

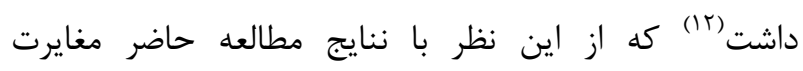
دارد.علت تفاوت مى تواند تفاوت سنى افراد مورد مطالعه (كروه سنى r-N سال) و نوع صبحانه مصرفى(غالبا صبحانه شيرين)

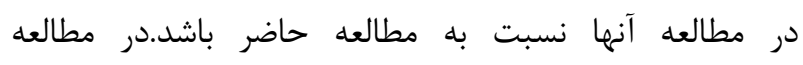

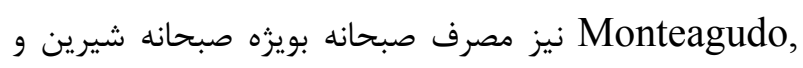
بيسكوييت بطور مشخصى موجب افزايش يوسيدگى در كودكان

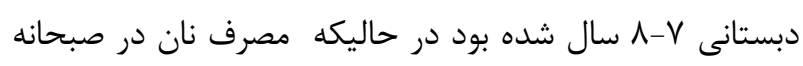
كمتر موجب يوسيدگى شده بود (11)

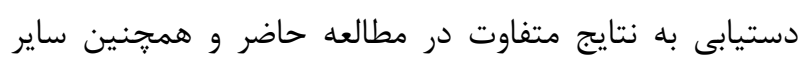

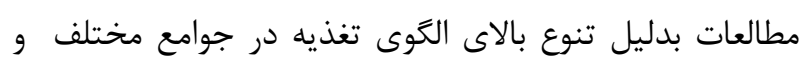

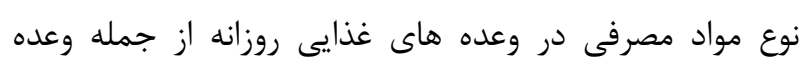
صبحانه باشد مواد مصرف مصرف غلات صبحانه در وعده صبحانه محبوبيت زيادى در باسد

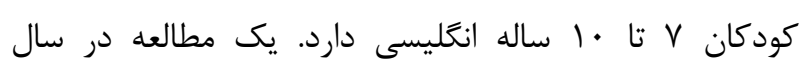

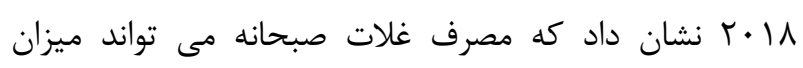

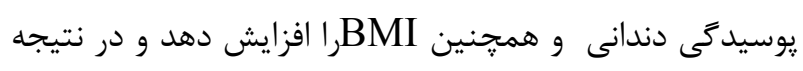

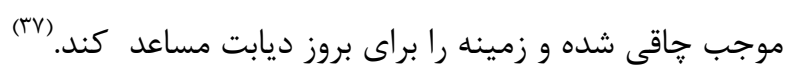

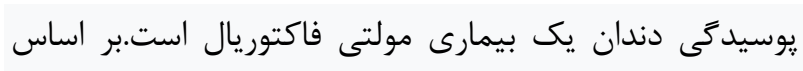

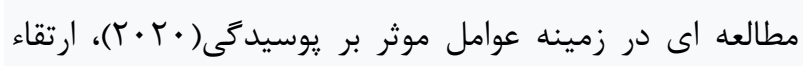

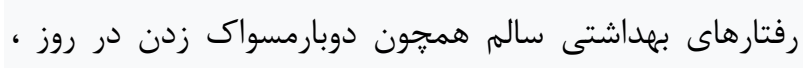

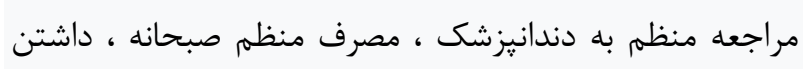

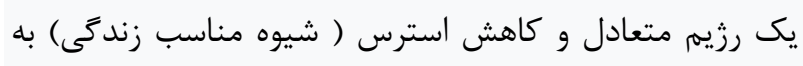

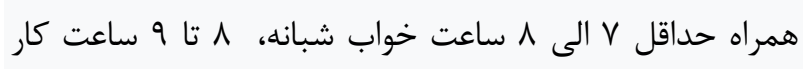
در طى روز و ورزش كافى ممكن است در سالهاى آينده به

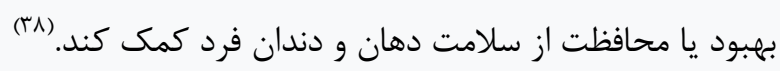

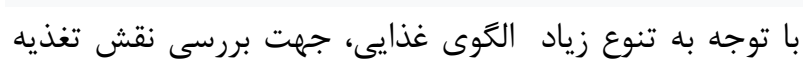

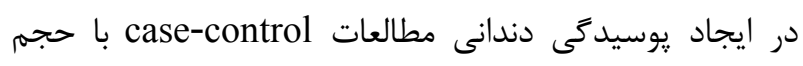
نمونه يكسان در دو كروه بِيشنهاد مى شود.

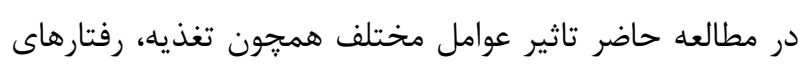

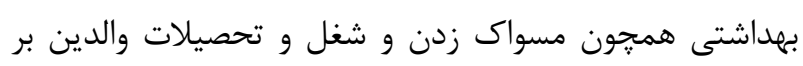
يوسيدكى دندانى شيرى و دائمى در سن 9 سالكَى ( دوره 


\section{References:}

1-Steyn N P , Temple N J. Evidence to support a food-based dietary guideline on sugar consumption in South Africa.BMC Public Health 2012;12:502.

2-Wiles NL, Green JM, Veldman FJ. The variety, popularity and nutritional quality of tuck shop items available for sale to primary school learners in Pietermaritzburg, South Africa. SAJCN 2011;24(3):129-35.

3-Oosthuizen D, Oldewage-Theron WH, Napier CE. The impact of a nutrition programme on the dietary intake patterns of primary school children. SAJCN $2011 ; 24(2): 75-81$.

4-Postma TC, Ayo-Yusuf OA, Van Wyk PJ.Sociodemographic correlates of early childhood caries prevalence and severity in a developing countrySouth Africa. Int Dent J 2008, 58(2):91-7.

5-MacIntyre UE, Du Plessis JB .Dietary intakes and caries experience in children in Limpopo Province. South Africa. SADJ 2006,;61(2):058-063.

6) McDonald R.E, Avery D.R, Dean J.A. Dentistry for the child and adolescent. $8^{\text {th }}$ ed. Mosby, St. Louis. 2004; chap 10. P: 205, 213.

7-Yousofi M, Behrouzpour K, Kazemi S, Afroughi S. Dental Caries and Related Factors among 7-12 Yearold School Children in Yasuj, Iran, in 2014. Armaghane danesh. 2015; 20 (9) :836-47.

8-Harris R, Gamboa A, Dailey Y, Ashcroft A. One-toone dietary interventions undertaken in a dental setting to change dietary behaviour. Cochrane Database Syst Rev. 2012:CD006540. https://doi.org/10.1002/14651858. CD006540

9- Obregón-Rodríguez N, Fernández-Riveiro P, Piñeiro-Lamas M.,Smyth-Chamosa E, MontesMartínez A,Suárez-Cunqueiro M..Prevalence and caries-related risk factors in Schoolchildren of 12and 15-year-old: a cross-sectional study. BMC Oral Health 2019; 19:120

10- Dye BA, Shenkin JD, Ogden CL, Marshall TA, Levy SM, Kanellis MJ. The relationship between healthful eating practices and dental caries in children aged 2-5 years in the United States, 1988-1994. JADA. 2004;135: 55-66.

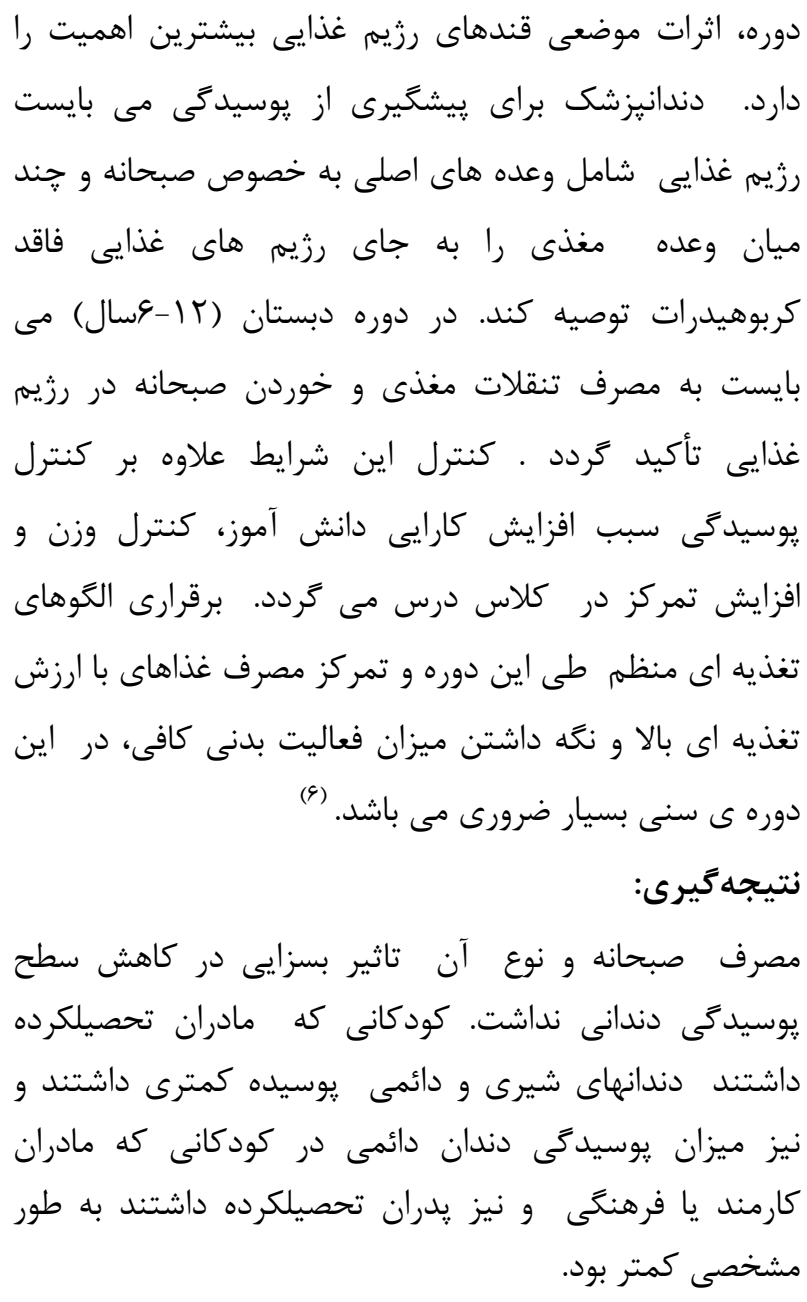


11-Monteagudo C, Téllez F, González LH , IbañezPeinado D ,Mariscal-Arcas M, Olea-Serrano F. School dietary habits and incidence of dental caries. Nutr Hosp 2015;32(1):383-88.

12- Bae J, Obiang Obounou BW.Presence of Dental Caries Is Associated with Food Insecurity and Frequency of Breakfast Consumption in Korean Children and Adolescents. Prev Nutr. Food Sci. 2018;23(2):94-101

13-Nematollahi H,Mehrabkhani M,Sheikhani MM. Investigate the relationship between diet and incidence of early caries in preschool children in Birjand. Dentistry J Shiraz Med Sci 2007;8(1):70-85

14-Basha S, Swamy HS. Dental caries experience, tooth surface distribution and associated factors in 6and 13- year- old school children from Davangere, India. J Clin Exp Dent. 2012 Oct; 4(4): e210-e216.

15-Greene JC, Vermillion JR. The simplified oral hygiene index. J Am Dent Assoc 1964; 68: 7-13.

16-Zafersoy,Akarslan,Sadik B,Sadik E,Erten H.Dieatary habits and oral health related behaviors in relation to DMFT indexes of a group of young adult patients attending a dental school .Med Oral Cir Bucal 2008;13(12):E800-7.

17-Eslamipour F, Borzabadi-Farahani A, Asgari I. The relationship between aging and oral health inequalities assessed by the DMFT index. Eur J Paediatr Dent. 2010; 11(4):193-9.

18-Al-Rafee MA, Al-Shammery AR, Al-Rumikan AS, Pani SC. A Comparison of Dental Caries in Urban and Rural Children of the Riyadh Region of Saudi Arabia. Front Public Health. 2019;7:195.

19-Wang Z, Rong W, Zhang Y, Zeng X, Li Z, Liu Z ,et al. Prevalence and contributing factors of dental caries of 6-year-old children in four regions of China. Peer J 2019; 7: e6997. PMCID: PMC6546074

20- Wang X. Report of the fourth national oral health survey. People's Medical Publishing House; Beijing: 2018.

21-Yee R, David J, Khadka R. Oral cleanliness of 1213-year-old and 15-year-old school children of Sunsari District Nepal. J Indian Soc Pedod Prev Dent 2006; 24(3):146-51.

22-Mielnik-Błaszczak M, Skawinska M, Janus M, et al. The Evaluation of Oral Hygiene in Children Affected with Epilepsy from Lublin Area. Dent. Med. Probl 2009; 46(2): 234-38.

23-Aabelusi GA, Jeboda So. Oral health status of 12year-old Nigerian children. West Afr J Med 2006; 25(3): 195-8.

24-Ullah MS, Aleksejuniene J, Eriksen HM. Oral Health of 12-year-old Bangladeshi children. Acta odontologica scandinavica 2002; 60(2): 117-22.

25-Polk DE, Weyant RJ, Manz MC. Socioeconomic factors in adolescents' oral health: are they mediated by oral hygiene behaviors or preventive interventions? Community Dent Oral Epidemiol 2010;38(1):1-9
26-Marshal T.A, Eichenberger-Gilmore JM, Broffitt BA, Warren JJ, Levy SM. Dental caries and childhood obesity: roles of diet and socioeconomic status. Community Dent Oral Epidemiol. 2007; 35(6):449-58. 27-Campus G, Lumbau A, Lai S, Solinas G, Castiglia P. Socio-economic and behavioural factors related to caries in twelve-year-old Sardinian children. Caries Res. 2001; 35(6):427-34.

28-Gluser-Ammann P, Lussi A, Bürgin W, Leisebach TDental knowledge and attitude toward school dentalhealth programs among parents of kindergarten children in Winterthur. Swiss Dent J 2014;124(7-8):770-83.

29-Freeman R, Breistein B, McQueen A, Stewart M. The dental health status of five-year-old children in north and west Belfast. Community Dent Health. 1997; 14(4):253-7.

30-Taani DQ. Relationship of socioeconomic background to oral hygiene, gingival status, and dental caries in children. Quintessence Int 2002; 33(3): 195-8. 31- Bruno-Ambrosius K, Swanholm G, Twetman S. Eating habits, smoking and toothbrushing in relation to dental caries: a 3-year study in Swedish female teenagers. Int J Paediatr Dent. 2005; 15(3):190-6.

32- Levine RS, Nugent ZJ, Rudolf MC, Sahota P. Dietary patterns, toothbrushing habits and caries experience of schoolchildren in West Yorkshire, England. Community Dent Health. 2007; 24(2):82-7.

33- Punitha V. C , Amudhan A , Sivaprakasam $\mathrm{P}$, Rathanaprabu V. Role of dietary habits and diet in caries occurrence and severity among urban adolescent school children. J Pharm Bioallied Sci. 2015; 7(Suppl 1): S296-S300

34-Sayegh A, Dini E.L, Holt R.D, Bedi R. Food and drink consumption, sociodemographic factors and dental caries in 4-5- year-old children in Amman.Jordan $\mathrm{Br}$ Dent J 2002; 193(1):37-42.

35- Sayegh A, Dini E.L, Holt R.D, Bedi R.Oral health, sociodemographic factors, dietary and oral hygiene practices in Jordanian children. J Dent 2005; 33:379-88. 36-Lim S. Cariogenicity of soft drinks, milk and fruit juice in low-income african-american children: a longitudinal study. J Am Dent Assoc 2008; 139(7): 95967.

37- Khehra, R , Fairchild, R. Morgan M.UK children's breakfast cereals - an oral health perspective. BDJ 2018; 225(5) :164-169

38- Singla N, Acharya S, Singla R, Nayak P. The Impact of Lifestyles on Dental Caries of Adult Patients in Udupi District: A Cross-Sectional Study. J Int Soc Prevent Communit Dent [Epub ahead of print] [cited 2020 Jul 22]. Available from: http://www.jispcd.org/preprintarticle.asp?id=2801 07

39-Qin Y, Zhang R, Yuan, B. et al. Structural equation modelling for associated factors with dental caries among 3-5-year-old children: a cross-sectional study. BMC Oral Health 2019;19: 102 